\title{
Methodological Approaches for Researching Complex Organizational Phenomena
}

\author{
Irena Ali \\ Joint \& Operations Analysis Division, Defence Science and \\ Technology Organisation, Department of Defence, \\ Canberra ACT, Visiting Research Fellow, School of Business, \\ University of New South Wales, Canberra Campus, \\ Canberra, Australia
}

\author{
irena.ali@dsto.defence.gov.au
}

\begin{abstract}
Organizations face an increasingly turbulent environment requiring flexibility and agility of processes and structures. Therefore, it is necessary to examine the interaction between formal organizational structures and informal networks in fulfilling these needs. A considerable body of evidence about informal collaborative arrangements in organizations exists, pointing to their importance in achieving results. This paper presents methodological considerations in an in-depth investigation of the complementary roles played by formal and informal structures in meeting the information and resource needs of people operating in an environment characterized by volatility, high tempo, and uncertainty. It argues that a new methodological approach is needed for this type of study. The research methods chosen for the study are discussed and justified in terms of the research problem. The essence of this paper is to detail the methodology used and draw lessons on this in light of its application.
\end{abstract}

Keywords: formal organization, informal networks, organizational dynamic, research methods, qualitative analysis, sensemaking, Cynefin framework.

\section{Introduction}

Organizations face an ever increasingly turbulent environment requiring agility (robustness, flexibility, and adaptability) of organizational processes, efficient informing systems, and flexible management arrangements to operate effectively in such environments (Atkinson \& Moffat, 2005; NATO, 2006). Organizations are complex systems (Anderson, 1999; Stacey, 2001), they

Material published as part of this publication, either on-line or in print, is copyrighted by the Informing Science Institute. Permission to make digital or paper copy of part or all of these works for personal or classroom use is granted without fee provided that the copies are not made or distributed for profit or commercial advantage AND that copies 1) bear this notice in full and 2) give the full citation on the first page. It is permissible to abstract these works so long as credit is given. To copy in all other cases or to republish or to post on a server or to redistribute to lists requires specific permission and payment of a fee. Contact Publisher@,InformingScience.org to request redistribution permission. are "...dynamic systems of adaptation and evolution that contain multiple parts which interact with one another and the environment" (Morel \& Ramanujam, 1999: p. 278). In the context of this research, an organization is regarded as a system comprising rules, policies, procedures, and defined roles (formal structure) within which individual agents or groups of agents operate and interact 
(formal and informal structures). While in some operational conditions different structures within organizations adhere to known formal processes, under other circumstances they exhibit behavior in which regularity and predictability is lost and they interact with each other in informal ways. In complex organizations, formal and informal structures co-exist and interact with each other.

Therefore, to meet the demands of the changing environment organizations need to explore how individuals construct their own reality in such contexts and to understand the dynamic of interaction between formal and informal organizational structures. Likewise, researchers in the fields of informing science and organizational management need to employ a variety of research methods to make sense of these varied conditions to study complex organizational phenomena. In this context complexity theory and associated with it frameworks have implications for the methodologies used to understand complex organizations.

Gill (2013) advocates that to cope with complexity we need to understand it. This must include a discourse on methods to study complex phenomena. This paper presents methodological considerations for an in-depth investigation of the complementary roles played by formal and informal structures in meeting the informing and resource needs of people operating in an environment characterized by volatility, high tempo, and uncertainty. It argues that approaches combining different methodological lenses are needed for this type of study. The research methods chosen for the study are discussed and justified in terms of the research problem. Preliminary outcomes and a wider discussion of this research in view of the research questions are reported in Ali (2011).The purpose of this paper is to detail the methodology used and draw lessons learned in light of its application and also to aid transdisciplinary approach to informing science.

\section{Background to the Study: Informal Networks and Organizations}

From the early days of hunter-gatherers to tribal warlords, formal organizational structures have been an integral part of society (Clegg \& Dunkerley, 1986). At the same time, informal and social networks are accepted part of life and the extent and the types of networks individuals form affects many aspects of their life from one's health, identity, and wellbeing to education, career advancement, and power in the organizations (Brass, Galaskiewicz, Greve, \& Tsai, 2004; Granovetter, 1983; Kilduff \& Tsai, 2003; Krackhardt, 1990; Krackhardt \& Hanson, 1993; Liccardi et al., 2007). In the field of knowledge management, knowledge distribution, and gaining competitive advantage, the importance of informal networks is well supported (Awazu, 2004; Cross, Parker, Prusak, \& Borgatti, 2001; Hoffman, Hoelscher, \& Scherif, 2005; Kurland \& Pelled, 2000; Plickert, Cote, \& Wellman, 2007). In disaster and emergency management, informal networks, due to their flexibility, adaptability, and fast information flows, have been shown to be crucial as disaster management seldom works according to standard operating procedures or neatly defined roles and responsibilities (Denning, 2006; Hyland, 2011; O'Brien \& Ali, 2006; O'Neil \& O'Brien, 2004). Understanding the role played by informal networks has been a focus of organizational research, including mapping informal interactions within an enterprise to organizational goals (Cross \& Prusak, 2002; Cross \& Thomas, 2009; Ehin, 2004).

In social science research since the 1940s, it was reported that the most fruitful concept to emerge was that of informal organization (Firey, 1948). Organizational theorists became aware that the formal organizational structure fails to capture numerous important aspects of communication in organizations, and they observed that informal networks provide the quickest means of communication and dissemination of information (Monge \& Contractor 2003). These networks develop spontaneously, irrespective of executive orders issued along communication lines of formal organization (Jablin \& Putnam, 2001; Robbins, Millett, Cacioppe, \& Waters-Marsh, 2001). 
The literature supports the notion that formal organizations are well equipped to deal with anticipated problems, and responsibility, authority and accountability measures are embedded in the system (Bennet \& Bennet, 2004; Fairtlough, 2005). However, formalization fails to cope with the non-rational dimensions of organizational behavior and a changing and complex operational environment (Mele, 2006; Rank, 2008). While formal and informal organizational structures have been extensively researched as separate entities, situated within different organizational systems and organizational communication flows (Mintzberg, 1980; Monge \& Contractor, 2003; Monge \& Eisenberg, 1987), in reality these structures not only exist alongside each other but are intertwined in organizational life (Rank, 2008; Zenger \& Lazzarini, 2002). While there seems to be a consensus amongst researchers and practitioners that organizational agents rely on both formal and informal coordination devices, side by side, in order to achieve set goals (Rank, 2008), there seems to be a lack of empirical studies looking at the issues that would make the entwinement of formal and informal organizational structures effective. Therefore, the area of what factors underpin a successful interaction between the formal and informal organizational structures still remains largely unexplored and this is addressed in this research.

\section{Objective of the Study and the Research Setting}

The objective of this research is to examine the relationship and interaction between formal and informal organizational structures in a rapidly changing operational environment. More specifically, to investigate factors that underpin interaction between formal and informal structures in such a way that will allow organizations to respond with agility to uncertain and changing operational environment, and to understand the role informal networks play in this organizational dynamic. This is still largely unexplored and somewhat difficult area to research (Ali, 2011; Zenger \& Lazzarini, 2002) and special consideration has been given to what data can be used, how the data can be analyzed, and how it is interpreted through a suitable holistic framework. In the context of this research organization is regarded as a system comprising policies and procedures (formal structure) within which individual agents or groups of agents operate and interact (formal and informal structures).

This research largely utilizes secondary data gathered for an earlier research that investigated issues relating to operating, making decisions, and multi-agency interactions in the context of the contemporary trends in warfighting. One hundred and forty six semi-structured, open ended interviews were conducted with a sample of the Australian Defence Forces (ADF) deployed to combat and humanitarian operations during 2001-2007 (Ali, Bopping, Hart, Pascoe, \& Warne, 2007). The phenomenon that emerged from data analysis for that earlier research warranted more in depth analysis and led to the formulation of research questions for this study.

Military organizations provide an ideal setting to study the interaction between the formal and informal organizational structures in complex environments because the military is a visibly hierarchical organization with clearly defined lines of communication and authority but where individuals form informal connections across functional groups and hierarchies. Also, the military operational landscape is characterized by change and uncertainty, and exposure to the vagaries of the political, societal, and economic climate. Moreover, operations of vastly different nature can take place simultaneously that require collaboration across services, nations, government and non-government organizations, and with civilians and reservists. This collaboration usually involves formal and informal means. 


\section{Research Design and Methodological Approach}

Four broad research questions are explored in this study:

- What factors give rise to informal network activity in complex operational environments?

- What are the characteristics and modus operandi of these networks?

- How do informal networks contribute to organizational goals in complex environments?

- What are the enabling factors that support coexistence of informal networks and the formally structured organization in complex operating environments to facilitate agile organizational responses to operational imperatives?

These questions are exploratory and seek to gain understanding and uncovering of insights and perceptions of a phenomenon in social reality. These underpinnings align with a qualitative approach based on interpretive and constructivist paradigms (Creswell, 2009; Denzin \& Lincoln, 2005; Ponterotto, 2005; Punch, 2005). This research comprises two phases. The first involves indepth template analysis to identify major themes (King, 2004) and the Cynefin framework to gain different perspective on the aspects of the data (Kurtz \& Snowden, 2003). In the second phase the findings of the Phase 1 analysis were corroborated with a sample of military personnel who had more recent operational experience than that of original data set. The overview of research design is depicted in Figure 1.

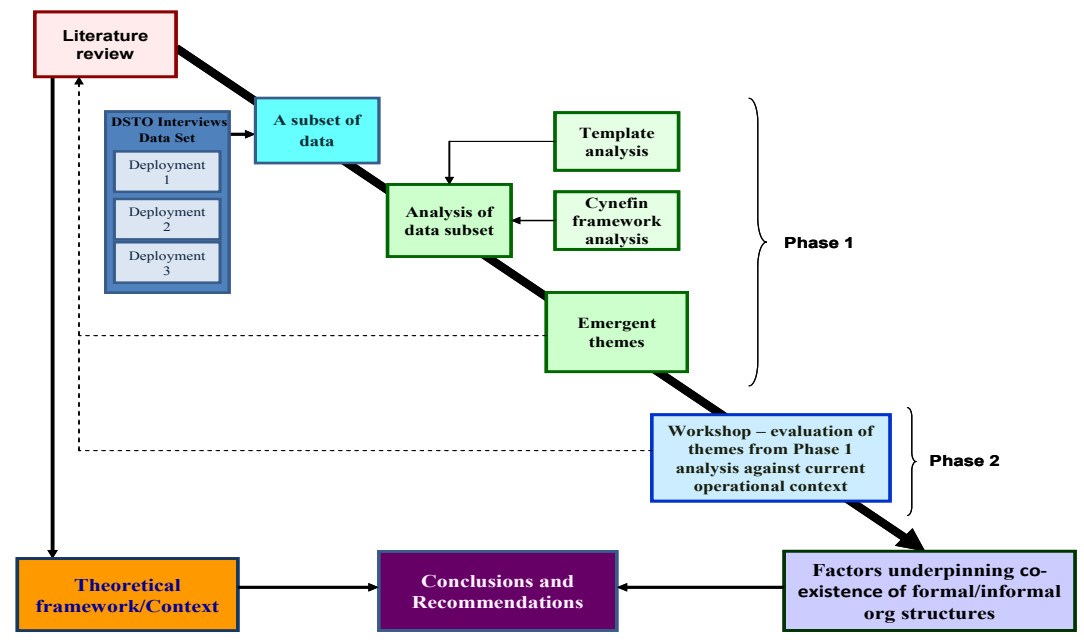

Figure 1: Overview of the research design

\section{Phase 1 - Template and Cynefin Framework Analysis}

Since coding and thematic reduction of the data is the starting activity for qualitative analysis (Creswell, 2009; Punch, 2005), the analytical approach for in-depth analysis of the data set in this research largely followed the conventions of template analysis (King, 2004). It is a particular way of thematically analysing qualitative data where the researcher produces a list of codes (template) representing themes identified in the textual data. Template analysis is suited for research that seeks to discover underlying causes for human action and through the use of code terms at different levels of specificity it secures reliability of findings (King, 2004; Waring \& Wainwright, 2008). 
The vast majority of the interviews were recorded, transcribed into electronic format and entered into N'Vivo, a tool for processing qualitative data. It allows the researcher to apply template analysis by indexing segments of the text to particular themes, then to carry out complex search and retrieval operations quickly, and link research notes to coding.

Through template analysis it became evident how pervasive the uncertainty was, not only in the context of the operational environment, but the extent to which the participants experienced that uncertainty and how it shaped interactions between informal networks and the formal organization. To study this it required a tool capable of depicting dynamics of both the environment and human behavior. The Cynefin framework was originally developed to help understanding of the different types of organizational systems (formal and informal) and associated decision-making models under varying degrees of uncertainty (Snowden, 2002; Snowden \& Boone, 2007). Practitioners in the sensemaking field advocate that Cynefin is particularly suited to study social complexity and to describe problems or opportunities in the environment individuals or organizations are operating in. Furthermore, the Cynefin framework arranges the issues facing decision-makers according to the degree to which the relationship between cause and effect can be determined or recognized (Schmidtchen, Boswell, Burnett, Kalloniatis, \& Taylor, 2008; Sivertsen, 2010) and, therefore, it is seen as an appropriate analytical tool for this research.

\section{What is the Cynefin sensemaking framework?}

Sensemaking is a cognitive as well as a social process requiring interaction and development of a collective mind, i.e., a shared sense of meaning in the situation (Paparone, Anderson, \& McDaniel, 2008). Thus sensemaking as a framework ties the cognitive perspective and social constructivism together (Pfeffer, 1981).

In this study the Cynefin sensemaking framework depicted in Figure 2 is used as an analytical tool for describing different circumstances of the operating environment, for describing activities of individuals in that environment, for mapping the path of activities as the circumstances change, and for explaining and illustrating the interactions between the formal organization and informal networks.
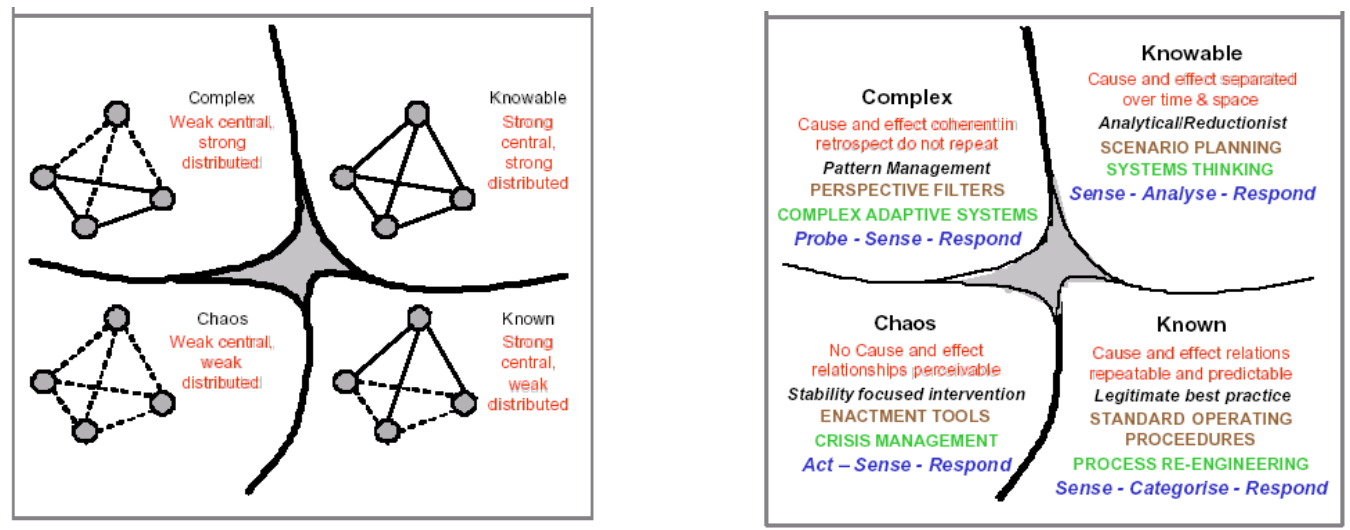

Figure 2: Domains of the Cynefin framework and respective connections strength

Literature describes several sensemaking models, for example, a cognitive Data/Frame model that is seen as a suitable model for improving sensemaking through training interventions (Sieck, Klein, Peluso, Smith, \& Harris-Thompson, 2007) or a behavioral model to aid team sensemaking (Powers, Stech, \& Burns, 2010). While these models are useful frameworks to enhance sensemaking of individuals or teams, they do not treat sensemaking in the context of the environment. The Cynefin framework advocates the use of narrative for understanding complexity and empha- 
sizes the social aspects of sensemaking while taking into account various environmental circumstances. It is a holistic sensemaking framework developed through research and practice (Snowden, 2002; Snowden \& Boone, 2007).

The Cynefin framework has five distinctive domains (Kurtz \& Snowden, 2003; Snowden \& Boone, 2007). 'Known' and 'knowable' do not refer to the knowledge of individuals. They are used in context of things that are known to society or the organization, depending on the interest at a given time. These domains are:

The Known or Simple - characterized by stability and clear relationship between cause and effect. Simple contexts, once properly assessed, require straightforward management and monitoring. The approach is to Sense - Categorize - Respond (SCR). This suits a vertical way of working with weak horizontal links and adherence to best practices is appropriate.

The Knowable or Complicated - in which the relationship between cause and effect requires analysis or other form of investigation, often leading to several options, and/or the application of expert knowledge. The approach is to Sense - Analyze - Respond (SAR). In such an environment vertical and horizontal links need to be strong and good practice rather than best practice, is more appropriate.

The Complex or domain of Emergence - in which the relationship between cause and effect can only be understood in retrospect. Emergent patterns can be perceived but not predicted. The approach, therefore, is to Probe - Sense - Respond (PSR) and then allow emergent practice. There are no 'right' answers and the need for increased levels of interaction and communication as well as creative and innovative approaches is greater. In this domain, the horizontal connections between individuals ideally need to be strong with weak vertical connections.

The Chaotic or domain of rapid response - there is no visible relationship between cause and effect at system level and no time to investigate or ask for input. Therefore, reducing turbulence and establishing order is important, and then sensing where stability is present and where it is not, i.e., sense reaction to initial intervention, and then respond by transforming chaos into complexity where patterns can emerge. Top-down or broadcast communication is imperative in those situations. The overall approach, therefore, is to Act - Sense - Respond (ASR). The connections between individuals in this domain should be weak or non-existent.

Disorder (the central shaded area) - a destructive state of not knowing what type of causality exists. In this domain decision-makers look at the same situation from different points of view and they will often revert to their own comfort zone in making a decision or conversely; it is a state of decision paralysis.

Furthermore, the right-hand domains (known/simple and knowable/complicated) are characterized as order, and the left-hand domains (complex and chaotic) as un-order. None of these four domains is more desirable than any other. The framework is used primarily to consider the dynamics of situations, decisions, perspectives, conflicts, and changes, and to recognize in which quadrant a given situation resides and what sensemaking approach is appropriate. The relationships between this framework and others in the literature, such as Contingency Theory and 'Wicked Problems' has been noted by Kalloniatis, Macleod, and Kohn (2010).

Because the Cynefin framework was originally developed to help in understanding formal and informal communities and interactions of structured processes and uncertain conditions, it is particularly suited to study social complexity and to describe problems prevailing in a given context (Kurtz \& Snowden, 2003; Snowden \& Boone, 2007; Verdon, 2005). 


\section{Application of Cynefin for this research}

The Cynefin framework is used to analyze the data retrospectively through two step process. In the first step the Cynefin framework is used to represent the organizational 'problem space' or the external context of a given instance of a deployment under study (Figure 3). Here, 'dots' of different color are placed in different domains of the Cynefin space in order to represent the state of the context or a situation at a given point in time. These 'dots' are also labeled to provide contextual information as interpreted by the researcher in terms of its attributes in relation to the particular Cynefin domain. Although these 'dots' are placed in various parts of a particular Cynefin domain, there is no specific 'value' attached to the 'dot's' position within the domain. Figures 3 and 4 are examples of the Cynefin analysis carried out in this study.

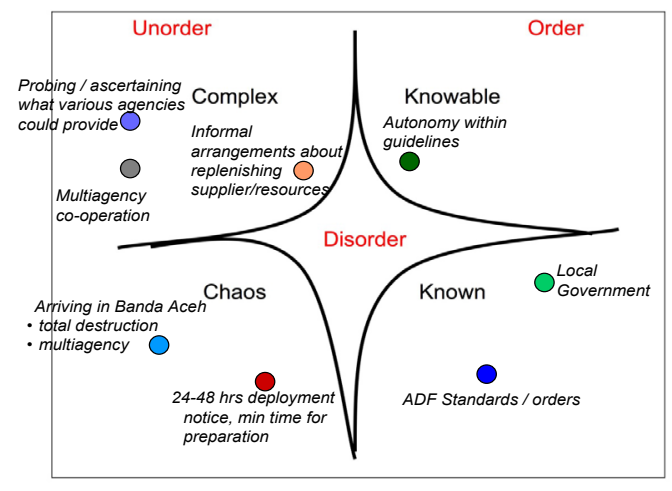

Figure 3: Operational 'problem space'

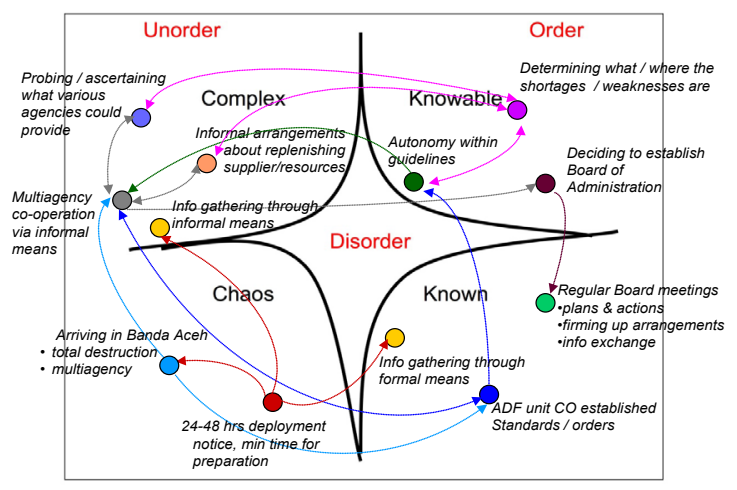

Figure 4: Operational 'approach space'

The second step sees the use of the Cynefin framework to represent the organizational or individual 'approach space'. In the approach space the lines and arrows represent individual or collective actions caused by a given situation and resulting in altering the set of circumstances deployed personnel found themselves in. To demonstrate which situation leads to an elected approach, the choice of color for the lines and arrows in the 'approach space' are the same as that for the 'dots' in the 'problem space'. Thereby, the correspondence between a state in the context and the associated organizational or individual response is aligned (Figure 4).

The examplein Figure 3 illustrates the issues faced by the individuals upon arrival in a disaster zone and the subsequent approaches used to deal with unfolding situations are depicted in Figure 4. The arrows represent interactions between individuals and between formal organizational structures and informal networks, information flows, and behaviors of individuals in various operational contexts. This analysis allows explication of the perspectives and sensemaking approaches of various stakeholders involved in changing operational conditions. By making these perspectives discernible, it is possible to determine organizational processes and command approaches to deal with the demands of the prevailing operational conditions. The essence of the Cynefin analysis is to represent an evolutionary path of the informal network that emerged in response to the changing environment. This analysis shows that all the operational context and activities span all quadrants of the framework and the interactions cross back and forth between the Un-ordered and Ordered domains. While there was a natural tendency to steer the situation in the 'clockwise' direction to bring some level of stability, there were also 'benefits' when the interactions moved 'anti-clockwise', as this led to different ways of working out and learning what brings desired results, and then incorporating these lessons into the system. Therefore, the 'clockwise' and 'anti-clockwise' movements between Cynefin domains illustrate the benefits to 
be had from traversing both directions. Incorporating lessons learnt from deployments about the workability of formal organizational processes is a key to improving agility.

The benefit gained from using the Cynefin framework to analyze the data was to understand and interpret the impact of different contingencies that emerged from the thematic data analysis in the dynamic environment and how the agents in the theatre attempted to interpret the unfolding situations. The Cynefin analysis showed how people are first driven to transform difficult problems, as they are framed, to get a different perspective on them and then steer them back to the known and familiar, i.e., the domain of Order. Conversely, if that approach does not bring the expected outcomes, they adopt approaches that are suited to the domain of Unorder. This indicates that the deployed personnel's responses were not following a random path. The Cynefin analysis demonstrates that, although subconsciously, they were quite methodical in the way they approached difficult problems during these deployments. This 'zig-zag' path through the Cynefin domains also suggests that planning in these instances represented responses to 'Wicked Problems' (Rittel \& Webber, 1973), where the path from problem formulation to solution is non-linear.

The Cynefin analysis supported by the template analysis demonstrates that efforts to shift the situation from uncertainty (Un-ordered domains) require extensive information sharing, trust, and a diverse set of interactions, both formal and informal amongst the individuals and agencies involved. These continuous interactions between and amongst individual and groups of agents, and inter-organizationally are necessary for collective sensemaking and contribute to forming a richer picture of the situation and to maintaining a shared understanding of what is required. This in turn led to the development of broad plans of action.

Overall, the analyses in Phase 1 led to deeper understanding, firstly, of the factors influencing informal network activity, their prevalence and efficacy during deployments under study and, secondly, the interaction between formal managerial and organizational processes, and informal networks in operational environment. These findings were further explored in a sensemaking workshop.

\section{Phase 2 - Sensemaking Workshop}

The aim of the workshop was to determine whether Phase 1 data analysis outcomes could be valid in terms of accuracy of interpretation of data analysis in view of more recent operational experience and to extend the research by discussing priorities and actions that could be taken to facilitate the coexistence of formal organization and informal networks in future operations.

The method chosen for this phase of the research draws on the theory of sensemaking nestled in complexity and the sense that individuals and groups make of past events and experiences. The data can be elicited by the means of narrative in the form of story or anecdote circles. The use of narrative or stories in organizations as a device for understanding complexity and as a sensemaking response to it is advocated by many writers in the field (Czarniawska, 1998; Putnam \& Fairhurst, 2001; Snowden, 1999, 2001; Weick, Sutcliffe, \& Obstfeld, 2005).

Generally, the process of sensemaking involving anecdote/story circles has three distinctive parts. It starts with elicitation of anecdotes from participants, followed by a reflection/sensemaking session and then designing an intervention model (O'Toole, Talbot, \& Fidock, 2008). This process has been adapted and the sensemaking workshop used for Phase 2, although drawing on the principles of narrative techniques, followed, to a large degree, the focus group processes. Table 1 summarizes the respective approaches. 
Table 1: Comparison between story circle model and Phase 2 workshop

\begin{tabular}{|l|l|}
\hline \multicolumn{1}{|c|}{ Process of anecdote/story circles } & \multicolumn{1}{c|}{ Adapted process for Phase 2 workshop } \\
\hline $\begin{array}{l}\text { Elicitation/generation of anecdotes from partic- } \\
\text { ipants }\end{array}$ & $\begin{array}{l}\text { Immersion of participants in the stories select- } \\
\text { ed according to the themes that emerged from } \\
\text { data analysis in Phase 1 }\end{array}$ \\
\hline $\begin{array}{l}\text { Reflection/sensemaking session, an iterative } \\
\text { process to generate insights and focus attention } \\
\text { on particular issues }\end{array}$ & $\begin{array}{l}\text { Discerning to what extent these stories reso- } \\
\text { nate with the participants' experiences and fo- } \\
\text { cus their attention on particular issues }\end{array}$ \\
\hline $\begin{array}{l}\text { Intervention model that involves designing of } \\
\text { interventions that the participants feel commit- } \\
\text { ted to }\end{array}$ & $\begin{array}{l}\text { Determining actions and methods to operation- } \\
\text { alise themes identified in Phase1 }\end{array}$ \\
\hline
\end{tabular}

Since the objective of the workshop was to align the findings from Phase 1 with more recent deployment experience and the initial interview program followed a design of a narrative enquiry and provided a rich source of data, therefore, there was no need to elicit further stories. The stories (anecdotes), considered representative of the themes that emerged from the template analysis (Phase 1), were chosen by the author and were grouped according to these themes.

The participants were asked to immerse themselves in these anecdotes and then discern the extent to which these stories resonate with them. By placing a 'red' or a 'green' sticker' on a given story the participants indicated whether they could relate to the issues depicted by a given anecdote, and also to indicate whether they found these examples to be a practice to be encouraged (green sticker) or something that should be discouraged (red sticker). Some of the anecdotes received multiple stickers, either red or green, whereas others did not evoke any response and remained unmarked. For example, the anecdotes depicting networking behavior, and in particular targeted networking, were widely endorsed by the workshop participants. Also, reliance on informal networks to obtain needed equipment or intelligence was seen as an appropriate use of informal connections, however, not so for classified information. An interesting case was where the responses to a given anecdote were polarized ranging from endorsement to complete disapproval of an approach. This illustrates that in a complex environment there is no one correct answer, as problems fall outside normal boundaries of decision making (Bolton \& Stolcis, 2008; Cilliers, 2000; Snowden $\&$ Boone, 2007) and operators or managers probe for solutions and respond in light of these probes.

The sensemaking component of this workshop was designed to explore the patterns and perspectives revealed in the chosen stories and to discern to what extent these stories resonated with the experiences of those with more recent operational experience. It involved determining the key issues emerging from the stories by writing brief comments regarding actions described in these anecdotes. The question that was posed to the participants was "what did you notice in these anecdotes/stories? After reading the stories, all participants wrote a short statement on a post-it note depicting the main message or a feeling evoked by a given story. The post-it notes were then placed around the appropriate themes. Thereafter, the participants, relying on group experience, were asked to cluster them into patterns that they saw emerging. An example of one of the clusters is depicted in Figure 5. These clusters were then rated according to their perceived importance to the ADF in being able to benefit from use of informal networks during operations. Each of the clusters was assigned a title or a heading which subsequently constituted the intervention subject.

During the 'intervention' stage of the workshop the participants were asked to indicate the relative importance to their practice of a given intervention theme by placing a mark (a dot), according to a sliding scale, on a sheet containing the intervention title, as illustrated in Figure 6 . The aim was not to obtain a consensus but to produce a range of options as perceived by the partici- 
pants. Thereafter, the participants worked in groups on the chosen intervention themes and were asked to find and suggest actions that could be implemented.

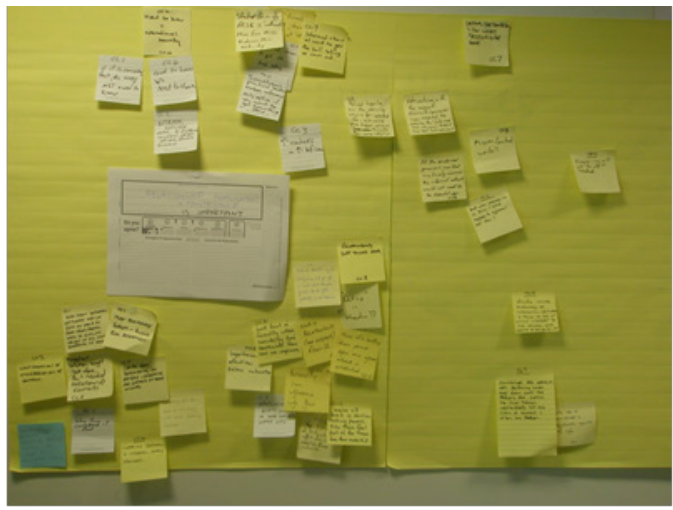

Figure 5: A cluster generated during the workshop

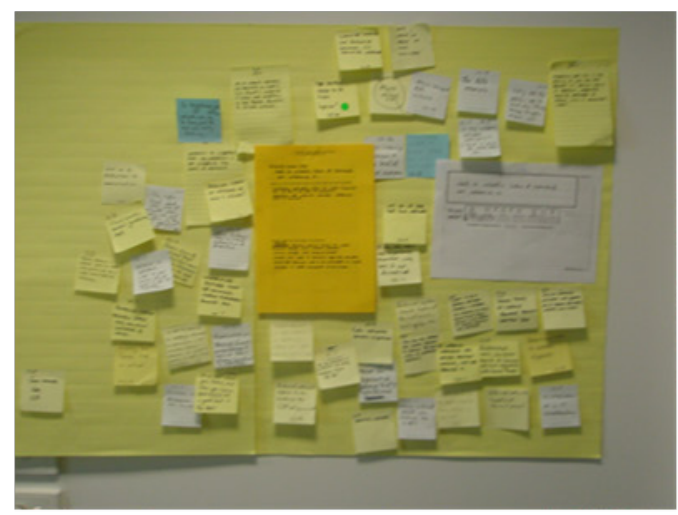

Figure 6: An example of 'dotmocracy' constituting intervention subject

As a last step, the participants were asked to indicate whether the dominant issues that emerged from the thematic analysis are adequate to optimize the coexistence of formal organization and informal networks during deployments. The analysis of interventions proposed by workshop participants for each dominant issue identified in Phase 1 indicates an interrelationship between them. The overall qualitative comments addressing the requirements for effective use of informal networks during deployment spanned areas of education and training, doctrine, and command arrangements. They pertain to building individual skills through education and training at all levels of the command chain and to creating enabling infrastructure by doctrinal and higher command guidance. Several workshop participants commented on the need for feedback programs to improve ineffective processes, leading to an organizational culture within which individuals will be empowered to collaborate and self-organize in responding to changing operational contexts. The specific outcomes on the need of a balance of formal and informal structures during deployments are reported elsewhere (Ali, 2011).

\section{Conclusions}

Researchers frequently combine different methods of data collection and analysis when studying the same social issue. This multi-field approach has been discussed in the area of social and informing sciences research and is a recognized way of validating research data and gaining wider perspectives (Miles \& Huberman, 1994: Silverman, 1985).

This study relied on personal lived experiences of participants as they interacted with the formal organization in the context of a changing operational environment. This necessitated approaches situated in organization and complexity theories. Both the changing operational environment and the interactions themselves meant that the participants were undergoing an iterative process of sensemaking of these circumstances. The template analysis provided descriptive insights of these phenomena and provided tangible examples that informal structures played a crucial role in attaining mission goals when formal organizational structures were perceived not responding with the required agility. The other insight gained from the template analysis pertains to the characteristics and modus operandi of these networks. This delineation provides a holistic picture about the nature of different networks and links them to contingencies that precipitated their formation.

A novel application of the Cynefin framework allowed analyzing and depicting of the intricate web of interactions when agents in the theatre of operations were probing and testing for possible 
solutions via formal and informal means. In this study, the Cynefin framework was applied as a theoretical and analytical tool. Its application has two-pronged benefits: as a tool to illustrate sensemaking activities carried out by the study participants and also as a sensemaking tool for the researcher herself to explore different perspectives of the data and thus to gain an integrated picture of that data. The way in which Cynefin has been used in this research enriches methodological approaches to study dynamic phenomena and thus contributes to broad organizational practice. Combining different methods to explore and obtain data enabled to identify factors supporting a mutually beneficial relationship between formal and informal organizational structures in complex environments.

Another methodological contribution of the research design of this study is in the area of using existing data in the form of stories to immerse new participants in the situations encountered by their predecessors. In this study an adaptation of anecdote circles was used to validate and to increase the credibility of interpretation of the data analysis from Phase 1 of the study. The benefits of adapting the method of anecdote circles is two fold: there was a clear advantage in saving time and resources by not eliciting new anecdotes, and more importantly, improved precision was gained by focusing on specific stories and addressing specific issues rather than sifting through the wide range of stories that is typically elicited during anecdote circles. This adaptation also extended the present research by discussing priorities and actions in future operations that could be taken to enable harnessing of strengths associated with formally structured organization and informal networks and making informal organizational structures complementary to the formal ones. Also, an important benefit resulting from Phase 2 was that the solutions proposed came from the deployed personnel rather than from the researcher.

There are some personal lessons learned from this study that will be of benefit to those who are planning to undertake research using qualitative methods into complex organizational phenomena. While there are advantages of using secondary data, one must be cognizant that it may not contain specific enough information and may need to be augmented. Also, it is easy to be overzealous while coding qualitative data. Too many code terms or too narrow distinctions between them mean that multiple codes are applied to individual fragments, thus decreasing the fidelity of retrieved data. Another lesson pertains to modification of existing methodological tools to suit a particular setting. Informing studies encompass a wide range of fields and by the same token, a wide range of research methods. It is therefore important to be innovative and take a 'risk' in applying methodological tools.

Cumulative learning from both phases of this research has shown that to study complex organizational phenomena it is necessary to apply a combination of different methodological approaches. Although these methods were used to study interactions between formal and informal structures in a military organization, these methods can be applied by informing science researchers to study dynamic phenomena in all types of organizations. The tasks of a leader and a manager in any organization are analogous to that of a military commander, similarly as those of deployed personnel and organizational staff. The difference may be that for organizational units and their leaders no 'enemy' exists, but the environment is nevertheless changing and capable of surprising.

It has been shown how the particular use of the Cynefin framework and the associated anecdote circles can be applied to organizational practice and in research. In practice, the Cynefin framework, with its multiple perspectives, is a useful tool to understand, reframe and re-perceive different issues and situations and to then propose a range of interventions. In research, these tools can be used to represent reality in different ways to investigate emergent issues and to study complex interactions. 


\section{References}

Ali, I. (2011) Coexistence or operational necessity: The role of formally structured organisation and informal networks during deployments. 16th International Command Control Research and Technology Symposium (ICCRTS), 21-23 June 2011, Quebec City, Canada: CCRP.

Ali, I., Bopping, D., Hart, D., Pascoe, C., \& Warne, L. (2007). The transition from network-centric warfare to networker-centric warfare: Outcomes of the human dimension of future warfighting task, (Restricted Access). DSTO Report CR-2007-0311. Defence Systems Analysis Division. Edinburgh, SA: Defence Science and Technology Organisation, Department of Defence.

Anderson, P. (1999). Complexity theory and organization science. Organization Science, 10(3), 216-232.

Atkinson, S., \& Moffat, J. (2005). The agile organization: From informal networks to complex effects and agility. Washingotn, DC: US Department of Defense Command and Control Research Program.

Awazu, Y. (2004). Knowledge management in distributed environments: Role of informal network players. 37th Hawaii International Conference on System Sciences, Hawaii: IEEE.

Bennet, A., \& Bennet, D. (2004). Organizational survival in the new world: The intelligent adaptive system. Oxford, UK: Elsevier.

Bolton, M. J., \& Stolcis, G. B. (2008). Overcoming failure of imagination in crisis management: The complex adaptive system. The Innovation Journal: The Public Sector Innovation Journal, 13(4), 2-12.

Brass, D. J., Galaskiewicz, J., Greve, H. R., \& Tsai, W. (2004). Taking stock of networks and organizations: a multilevel perspective. Academy of Management Journal, 47(6), 795-817.

Cilliers, P. (2000). What can we learn from a theory of complexity? Emergence, 2(1), 23-33.

Cleg, S., \& Dunkerly, D. (1986). Organization, class and control. London: Rutledge\& Kegan Paul.

Creswell, J. W. (2009). Research design: Qualitative, quantitative and mixed methods approaches. Los Angeles, CA: Sage Publications.

Cross, R., Parker, A., Prusak, L., \& Borgatti, S. P. (2001). Knowing what we know: Supporting knowledge creation and sharing in social networks. Organizational Dynamics, 30(2), 100-120.

Cross, R., \& Prusak, L. (2002). The people who make organizations go - or stop. Harvard Business Review (June), 105-112.

Cross, R., \& Thomas, R. J, (2009). Driving results through social networks: How top organisations leverage networks for performance and growth. San Francisco: Jossey-Bass, A Wiley Imprint.

Czarniawska, B. (1998). A narrative approach to organization studies. Thousand Oakes, CA: Sage Publications.

Denning, P. (2006). Hastily formed networks: Collaboration in the absence of authority. The SoL Journal, $7(1), 1-8$.

Denzin, N. K., \& Lincoln, Y. S. (2005). The Sage handbook of qualitative research (3rd ed.). Thousand Oaks, CA: Sage Publications.

Ehin, C. (2004). Hidden assets: Harnessing the power of informal networks. New York: Springer Science \& Business Media.

Fairtlough, G. (2005). Three ways of getting things done: Hierarchy, heterarchy and responsible autonomy in organizations. Dorset, UK: Triarchy Press.

Firey, W. (1948). Informal organization and the theory of schism. American Sociological Review, 13(1), $15-24$.

Gill, T. G. (2013). Complexity, cybernetics, and informing science: Building a better mousetrap. Systemics, Cybernetics and Informatics, 11(9), 53-68. 
Granovetter, M. (1983). The strength of week ties: a network theory revisited. Sociological Theory, 1, 201233.

Hoffman, J. J., Hoelscher, M. L., \& Scherif, K. (2005). Social capital, knowledge management, and sustained superior prerformance. Journal of Knowledge Management, 9(3), 93-100.

Hyland, A. (2011). Kinglake - 350. Melbourne: Text Publishing.

Jablin, F. M., \& Putnam, L. L. (2001). The new handbook of organizational communication: Advances in theory, research and methods. Thousand Oakes, CA: Sage Publications.

Kalloniatis, A., Macleod, I., \& Kohn, E. (2010). Agility in an extended space of constructible organisations. $15^{\text {th }}$ International Command and Control Research and Technology Symposium, June 2010, Santa Monica: CCRP.

Kilduff, M., \& Tsai, W (2003). Social networks and organizations. London: Sage Publications.

King, N. (2004). Using templates in the thematic analysis of text. In C. Cassell \& G. Symon (Eds.), Essential guide to qualitative methods in organizational research. London: Sage Publications.

Krackhardt, D. (1990). Assessing the political landsape: Structure, cognition, and power in organizations. Administrative Science Quarterly, 35(2), 342-369.

Krackhardt, D., \& Hanson, J. R. (1993). Informal networks: The company. Harvard Business Review (JulyAugust), 104-111.

Kurland, N. B., \& Pelled, L. H. (2000). Passing the word: Toward a model of gossip and power in the workplace. Academy of Managemnt Review, 25(1), 429-458.

Kurtz, C. F., \& Snowden, D. J. (2003). The new dynamics of strategy: Sense-making in a complexcomplicated world. IBM Systems Journal, 47(3), 462-483.

Liccardi, I., Ounnas, A., Pau, R., Massey, E., Kinnunen, P., Lewthwaite, S., ... \& Sarkar, C. (2007). The role of social networks in students' learning experiences. The $12^{\text {th }}$ Annual Conference on Innovation and Technology in Computer Science Education, Dundee, Scotland. 25-27Jun 2007, from http://iticse2007.computing.dundee.ac.uk

Mele, D. (2006). Ethics in management: Exploring the contribution of Mary Parker Follett. Barcelona: IESE Business School, University of Navarra.

Miles, M. B., \& Huberman, A. M. (1994). Qualitative data analysis: An expanded sourcebook. London: Sage Publications.

Mintzberg, H. (1980). Structure in 5's: A synthesis of the research on organization design. Management Science, 26(3), 322-341.

Monge, P. R., \& Contractor, N. S. (2003). Theories of communication networks. Oxford: Oxford University Press.

Monge, P. R., \& Eisenberg, E. M. (1987). Emergent communication networks. In L. L. Jablin, K. H. Roberts \& L. W. Porter (Eds.), Handbook of organizational communication (pp. 304-342). London: Sage Publications.

Morel, B., \& Ramanujam, R. (1999). Through the looking glass of complexity: The dynamics of organizations as adaptive and evolving systems. Organization Science, 10(3), 278-293.

NATO. (2006). Exploring new command and control concepts and capabilities, SAS-050 Final Report, January 2006.

O'Brien, F., \& Ali, I. (2006). Formal and informal networks during emergency situations: The impact for information strategy. $11^{\text {th }}$ ICCRTS - Coalition Command and Control in the Networked Era, Cambridge: CCRP. 
O'Neil, J., \& O'Brien, F. (2004). The role of informal communications in C2 decision making. $9^{\text {th }}$ ICCRTS Coalition Transformation: An evolution of people, processes, and technology to enhance interoperability, Copenhagen, Denmark: CCRP.

O'Toole, P., Talbot, S., \& Fidock, J. (2008). Anecdotally speaking: Using stories to generate organisational change. Qualitative Research Journal, 8(2), 28-42.

Paparone, C. R., Anderson, R. A., \& McDaniel, R. R. Jr. (2008). Where military professionalism meets complexity science. Armed Forces and Society, 34, 433-449.

Pfeffer, J. (1981). Power in organizations. Marshfield, MASS: Pitman.

Plickert, G., Cote, R. R., \& Wellman, B. (2007). It's not who you know, its how you know them: Who exchanges what with whom? Social Networks. 29, 405-429.

Ponterotto, J. G. (2005). Qualitative research in counseling psychology: A primer on research paradigms and philosophy of science. Journal of Counseling Psychology, 52(2), 126-136.

Powers, E., Stech, F., \& Burns, K. (2010). A behavioral model of team sensemaking. The International C2 Journal, 4(1), 1-10.

Punch, K. F. (2005). Introduction to social research: Quantitative and qualitative approaches. London: Sage Publications.

Putnam, L. L., \& Fairhurst, G. T. (2001). Discourse analysis in organizations: Issues and concerns. In F. M. Jablin \& L. L. Putnam (Eds), The new handbook of organizational communication (pp. 78-136). Thousand Oaks, CA: Sage Publications.

Rank, O. N. (2008). Formal structures and informal networks: Structural analysis in organizations, Scandinavian Journal of Management, 24, 145-161.

Rittel, H. W. J., \& Webber, M. M. (1973) Dilemmas in general theory of planning. Policy Sciences, 4, 155169.

Robbins, S. P., Millett, B. Cacioppe, R., \& Waters-Marsh, T. (2001). Organizational behaviour. Frenchs Forrest, NSW: Prentice Hall, Pearson Education Australia.

Schmidtchen, D., Boswell, S., Burnett, M., Kalloniatis A., \& Taylor, R. (2008). The future of command and control: Questions, observations and reflections. Australian Defence Force Journal, 175, 29 -42.

Sieck, W. R., Klein, G. Peluso, D. A., Smith, L., \& Harris-Thompson, D. (2007). FOCUS: A model of sensemaking. Technical Report 1200. Arlington, Virginia: United States Army Research Institute for the Behavioral and Social Sciences.

Silverman, D. (1985). Qualitative methods and sociology. Aldershot: Gower Pub.

Sivertsen, M. (2010). Cognitive Kanban: Improving decisions in a complex world. Lean Software and Systems Conference, Buckhead, Atlanta, 21-23 April 2010.

Snowden, D. (1999). Liberating knowledge: Understanding the sense making communities in the complex ecologies of the modern organisation. Liberating Knowledge (Jan): Caspian Publishing.

Snowden, D. (2001). Narrative patterns: The perils and possibilities of using story in organizations. Journal of Knowledge Management, 4(10), 1-5.

Snowden, D. (2002). Complex acts of knowing - Paradox and descriptive self-awareness. Journal of Knowledge Management (Special Edition), 6(2), 1-14.

Snowden, D., \& Boone, M. E. (2007). A leader's framework for decision making. Harvard Business Review, 85(11), 68-76.

Stacey, R. D. (2001). Complex responsive processes in organizations. Oxon: Routledge.

Verdon, J. (2005). Transformation in the CF: Concepts towards a theory of human network-enabled operations. Ottawa, Canada: Directorate of Strategic Human Resources National Defence. 
Waring, T., \& Wainwright, D. (2008). Issues and challenges in the use of template analysis: Two comparative case studies from the field. The Electronic Journal of Business Research Methods, 6(1), $85-94$.

Weick, K. E., Sutcliffe, K. M., \& Obstfeld, D. (2005). Organizing and the process of sensemaking. Organization Science, 16(4), 409-421.

Zenger, T. R., \& Lazzarini, S. G. (2002). Informal and formal organization in new institutional economics. The New Institutionalism in Strategic Management, 19, 277-305.

\section{Biography}

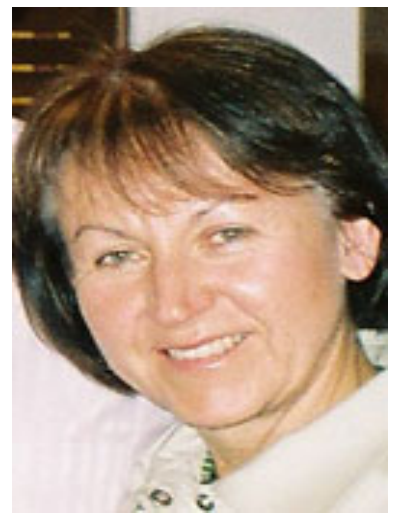

Irena Ali is a Defence Scientist and she joined Defence Science and Technology Organisation (DSTO) in Australia in 1999. Irena's educational background spans fields of biomedical science (BApplSc), Information Studies (Grad Dip Lib \& Grad Dip Arts (Info St), MA by research (Info St), and Information Systems $(\mathrm{PhD})$ with special interest in socio-organizational issues in complex environments. In 2009 she has been a recipient of the Secretary of Defence Fellowship to investigate factors associated with the formal organization and informal networks that affect the ability of the organization to operate and survive in a complex environment. Irena has an extensive research experience and is a member of a team responsible for researching and developing the human and organisational aspects of learning, knowledge mobilization, sensemaking, command and control, and situation awareness. She has published and presented both nationally and internationally in the field of organizational and social learning, human dimension of NCW and future warfare, fatigue and shift design, measuring situation awareness, and co-existence of formal and informal organizational structures in complex environments (over 60 publications). In her free time Irena is pursuing her culinary passion for hot and spicy food and enjoys skiing, bush walking, cycling, and snorkeling. 